\title{
Did Negative News Regarding the Oxford AstraZeneca Vaccine end in Vaccine Hesitancy? A Repeated Cross-Section Event Study from the UK
}

David Comerford ( $\nabla$ david.comerford@stir.ac.uk)

University of Stirling

Olivia Olivarius

University of Stirling

David Bell

University of Stirling

Alison Dawson

University of Stirling

Tamara Brown

University of Stirling

Lesley McGregor

University of Stirling

Cath Pemble

University of Stirling

Louise McCabe

University of Stirling

Elaine Douglas

University of Stirling

\section{Research Article}

Keywords: Vaccine hesitancy, risk perception, belief updating, naturalistic, event study

Posted Date: April 12th, 2021

DOI: https://doi.org/10.21203/rs.3.rs-355311/v2

License: (c) (i) This work is licensed under a Creative Commons Attribution 4.0 International License.

Read Full License 


\title{
Did Negative News Regarding the Oxford AstraZeneca Vaccine end in Vaccine Hesitancy? A Repeated Cross-Section Event Study from the UK
}

\author{
David A. Comerford*, Olivia Olivarius, David Bell, Alison Dawson, Tamara Brown, Lesley \\ McGregor, Cath Pemble, Louise McCabe, Elaine Douglas. \\ University of Stirling
}

\begin{abstract}
Vaccine hesitancy is influenced by perceived risk and benefits. On March $15^{\text {th }} 2021$ various countries suspended use of the Oxford AstraZeneca vaccine against Covid-19 following deaths arising from blood clots. The story became headline news and online search querying vaccine safety increased. What happened to Covid-19 vaccine intentions? We were collecting relevant data at the time. Our survey asked UK adults if they intended to get the vaccine and measured their attitudes towards it. Data collection from respondents before coverage of the story reached its peak (March $12^{\text {th }}-15^{\text {th }} ; n=241$ ) was compared with responses after the peak (March $17^{\text {th }} ; n=305$ ). Our data show no reductions in intentions or attitudes. Our study is uniquely positioned to analyse real-world responses and indicates that media coverage of this story did not reduce intention to take up the vaccine in the UK.

Keywords: Vaccine hesitancy, risk perception, belief updating, naturalistic, event study

* Address for correspondence: David Comerford, Economic Division, Stirling Management School, david.comerford@stir.ac.uk, 01786467317. Data, syntax files and ethics approval for this study can be found at https://osf.io/k6gm7/. This research is funded by the Economic and Social Research Council (ESRC), as part of UK Research and Innovation's rapid response to Covid-19. Grant number: $\mathrm{ES} / \mathrm{V} 01711 \mathrm{X} / 1$.
\end{abstract}

Clinical trials have demonstrated that many of the vaccines developed against Covid-19 are effective $^{1,2}$. Their efficacy is necessarily limited if people refuse to receive them. A recent survey experiment on a representative sample of the UK population found that exposure to negative misinformation about a Covid-19 vaccine reduced intention to vaccinate by 6.2 percentage points ${ }^{3}$. This finding suggests cause for concern for two reasons. First, herd immunity can only be achieved if uptake of the vaccine is high; it has been estimated that 65.5 percent of the UK population would need to be vaccinated if the pandemic is to be contained ${ }^{4}$. Second, the UK public has been exposed to a highly publicised negative news story regarding its most-widely used vaccine ${ }^{5}$, that produced by AstraZeneca (henceforth the AZ vaccine). On the evening of March $15^{\text {th }}$ a lead story on adio $^{6}$ and television news ${ }^{7}$ 
reported that France, Germany, Italy and some other European countries had suspended use of the $\mathrm{AZ}$ vaccine following deaths arising from blood clots. The following day, the story was front-page news on UK newspapers across the spectrum (Figure 1). Within days the European Medicine's Agency had pronounced that the AZ vaccine's benefits outweighed its risks and most countries resumed delivery of it $^{8}$. Still, commentators from the science community and media alike have raised concerns about how the news event might impact public trust in the vaccine ${ }^{8,9}$.

The current research describes the effect of these events on intentions to take a vaccine against Covid-19 and on attitudes to vaccination against Covid-19. We happened to have collected data as the story was gathering pace, over the period Friday March $12^{\text {th }}$ to the morning of Monday March $15^{\text {th }}$. We put our survey out again on the morning of Wednesday March $17^{\text {th }}$, immediately after the story had reached peak exposure.

\section{The Blood Clot / Vaccine Suspension Story}

On the evening of Monday, March $15^{\text {th }}$ the lead story on the $6 \mathrm{pm}$ Radio 4 News broadcast ${ }^{5}$ and the $7 \mathrm{pm}$ Channel 4 television news ${ }^{6}$ was that various European countries, including France, Germany and Italy, had suspended use of the AZ vaccine. Channel 4 correspondent Victoria MacDonald reported that this was "because of these reports of blood clots and some deaths" 6 .

On Tuesday the story was the lead headline on British newspapers across the board, from the left-leaning Guardian ${ }^{10}$ to the right-leaning Telegraph $^{10}$, from the populist Daily Mail ${ }^{10}$ to the Financial Times $^{9}$ (Figure 1). 
Figure 1: Screenshot of Front Page of the Daily Mail ${ }^{6}$ (left) and Financial Times ${ }^{7}$ (right) print editions from Tuesday March $16^{\text {th }}$.

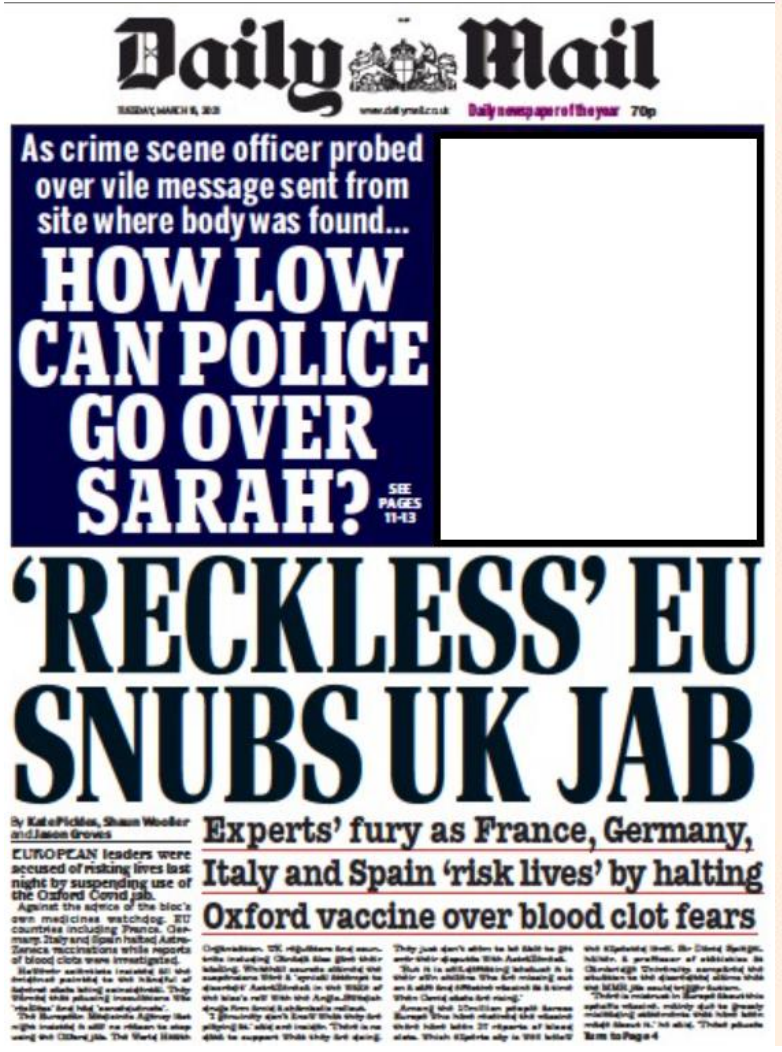

\section{FINANCIAL TIMES}

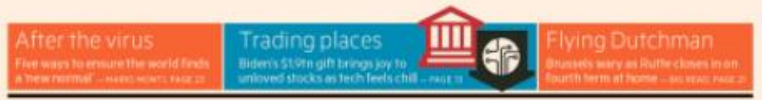

AstraZeneca jab rollout paused in Europe over blood clot fears

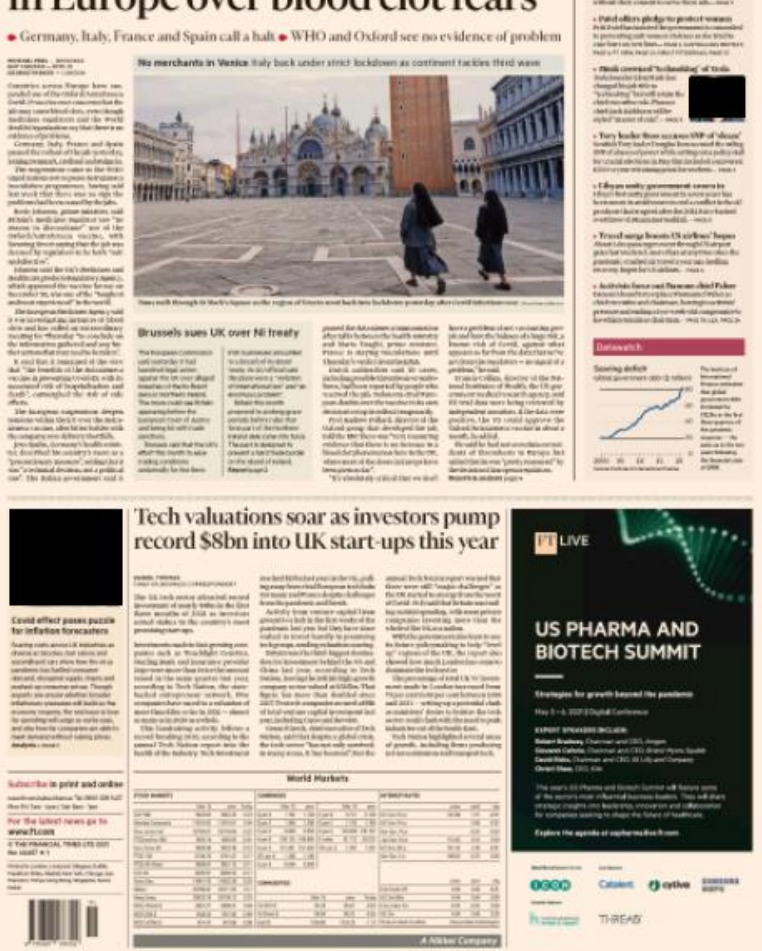

Table 1: Timeline of Events

\begin{tabular}{|c|c|c|c|}
\hline Day & Event & UK Media coverage & $\begin{array}{l}\text { Data } \\
\text { collection } \\
\text { activity }\end{array}$ \\
\hline Thursday 11 & $\begin{array}{l}\text { Iceland, Denmark and } \\
\text { Norway suspend use of the } \\
\text { AZ vaccine amid blood clot } \\
\text { fears. }{ }^{14}\end{array}$ & \multirow{2}{*}{$\begin{array}{l}\text { None that we can find. } \\
\text { Figure } 2 \text { also suggests the } \\
\text { suspensions were not } \\
\text { salient to the UK public. } \\
\text { Online search activity on } \\
\text { Thursday } 11^{\text {th }} \text { is as it had } \\
\text { been on Wednesday } 10^{\text {th }} \\
\text { and it falls on Friday } 12^{\text {th }} \text {. }\end{array}$} & \\
\hline Friday 12 & & & $\begin{array}{l}\text { 12.36pm: } \\
\text { Before data } \\
\text { collection } \\
\text { starts }\end{array}$ \\
\hline
\end{tabular}




\begin{tabular}{|c|c|c|c|}
\hline Saturday 13 & & & \\
\hline Sunday 14 & $\begin{array}{l}\text { 10.13am - Irish Minister for } \\
\text { Health tweets that Ireland } \\
\text { will suspend use of AZ } \\
\text { vaccine citing "new } \\
\text { information from Norway } \\
\text { that emerged late last } \\
\text { night"15 } \\
\text { Netherlands suspends use } \\
\text { of AZ vaccine on Sunday } \\
\text { night. }\end{array}$ & $\begin{array}{l}\text { 1pm - BBC Radio } 4 \text { current } \\
\text { affairs program "The } \\
\text { World This Week" does } \\
\text { not discuss the blood clot } \\
\text { fears or the suspensions. } \\
\text { The news bulletin that } \\
\text { opens the program reports } \\
\text { the Irish suspension and its } \\
\text { link to the Norwegian } \\
\text { blood clots as the fourth } \\
\text { item }{ }^{16} \text {. }\end{array}$ & \\
\hline $\begin{array}{l}\text { Monday } 15 \\
\text { a.m. }\end{array}$ & $\begin{array}{l}\text { The European Medicines } \\
\text { Agency schedules an } \\
\text { extraordinary meeting for } \\
\text { Thursday to conclude on } \\
\text { the safety of the AZ } \\
\text { vaccine. }\end{array}$ & $\begin{array}{l}\text { 7.30am - Immediately after } \\
\text { the news bulletin on BBC } \\
\text { Radio 4's Today program } \\
\text { Prof. Andrew Pollard of } \\
\text { the Oxford Vaccine Group } \\
\text { was interviewed about the } \\
\text { Irish and Dutch } \\
\text { suspensions. }\end{array}$ & $\begin{array}{l}\text { 9.11am: } \\
\text { Before data } \\
\text { collection } \\
\text { stops }\end{array}$ \\
\hline $\begin{array}{l}\text { Monday } 15 \\
\text { p.m. }\end{array}$ & $\begin{array}{l}\text { By evening use of the AZ } \\
\text { vaccine has been suspended } \\
\text { in many European } \\
\text { countries, including France, } \\
\text { Germany and Italy. }\end{array}$ & $\begin{array}{l}\text { The story becomes a lead } \\
\text { headline e.g. BBC radio } 4 \\
6 \mathrm{pm} \text { news } 6 \text {; Channel } 4 \\
\text { television news at } 7 \mathrm{pm}^{7} \text {. }\end{array}$ & \\
\hline Tuesday 16 & & $\begin{array}{l}\text { The AZ story is frontpage } \\
\text { news on most UK papers }{ }^{10} \text {. }\end{array}$ & \\
\hline $\begin{array}{l}\text { Wednesday } \\
17\end{array}$ & & & $\begin{array}{l}\text { 10.56am: After } \\
\text { data collection } \\
\text { begins }\end{array}$ \\
\hline Thursday 18 & $\begin{array}{l}\text { An extraordinary meeting } \\
\text { of the European Medicines } \\
\text { Agency pronounces that the } \\
\text { benefits of the AZ vaccine } \\
\text { outweigh risks }{ }^{19} \text {. }\end{array}$ & & \\
\hline Friday 19 & $\begin{array}{l}\text { Many European countries } \\
\text { restart use of the Vaccine. }\end{array}$ & $\begin{array}{l}\text { Various UK newspapers } \\
\text { run the EMA's } \\
\text { pronouncement as their } \\
\text { frontpage headline (e.g. } \\
\text { "Jab is Safe" in Daily Mail, } \\
\text { Daily Express and Daily } \\
\text { Telegraph) }\end{array}$ & \\
\hline
\end{tabular}

A widely-expressed concern in media reports was how this news would impact public confidence in vaccination against Covid-19. On Monday evening Prof. Adam Finn pointed 
out on $\mathrm{BBC}$ radio's primetime current affairs program, $P M$, that this was "doing reputational damage to the vaccine and to vaccines in general" ${ }^{11}$. In a subheading on page 4 , the Financial Times asked "What Will This Mean for Public Confidence?"12. The Economist predicted that "doubts caused by a temporary halt are likely to persist", a view echoed in an opinion piece published by the British Medical Journal ${ }^{13}$.

The prominence given to the story in the media came suddenly on Monday afternoon though it had been brewing for several days. Table 1 presents a timeline of events ending on Friday March $19^{\text {th }}$ when front-page headlines reported the resumption of AZ use in many European countries.

A measure of the public concern around the safety of the vaccine is presented in Figure 2. It depicts Google Trends data for the month February $21^{\text {st }}$ to March $21^{\text {st }}$ within the UK for searches that include the terms "vaccine" and "safe". There is a clear uptick in search activity coincident with the events and media reporting described in Table 1. Search for the terms on the first day of our data collection, Friday $12^{\text {th }}$, is in line with the previous period and is $33 \%$

of the search activity on Monday March $15^{\text {th }}$, where it peaks. It remains high on Tuesday $16^{\text {th }}$, at $93 \%$ of the Monday's level. These data demonstrate that the blood clot/ AZ suspension story entered the public consciousness and caused sufficient concern to prompt the UK public to seek information online.

The question that this research seeks to answer is whether the public concern manifest in Figure 2 translated into vaccine hesitancy.

Figure 2. Google Trends Graph mapping searches including the words "vaccine" and "safe" originating within the UK in the period February $21^{\text {st }}$ to March $21^{\text {st }}$ 
vaccine safe

Search term

$$
\text { : } \quad+\text { Compare }
$$

United Kingdom $\nabla \quad$ Past 30 days $\nabla \quad$ All categories $\nabla \quad$ Web Search $\nabla$
$1<<$

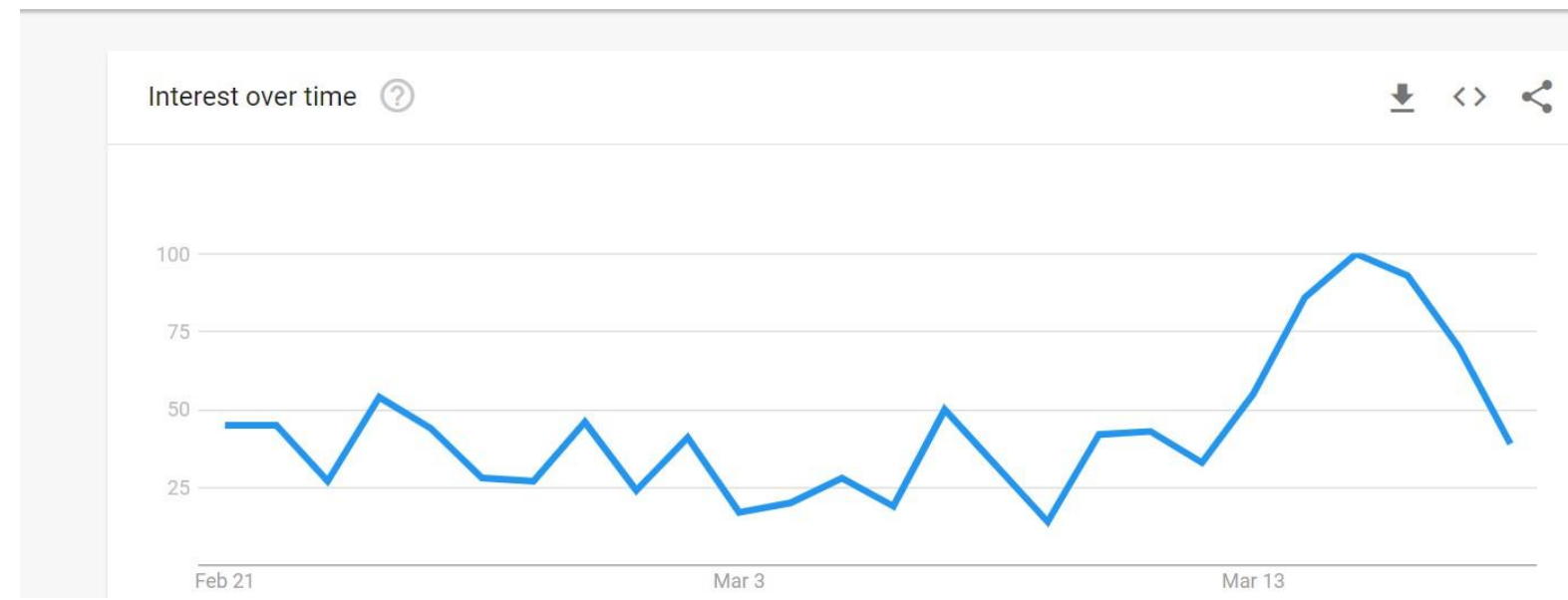

Note: We use this search term because it encompasses various more specific formulations e.g. "is the Covid vaccine safe?" and "is the Oxford AstraZeneca vaccine safe?"

\section{Results}

Table 2 describes the characteristics of our before and after samples. The sample of core interest to our study is those respondents who have not yet been vaccinated because this is the group who answered our intention to vaccinate question. The first row of Table 1 shows that there is no significant difference in the likelihood of being vaccinated between our before and after samples. The rows that follow restrict the sample to those who have not been vaccinated and so answered the intentions question $(n=433)$. There are no differences in the observable characteristics of the two groups. This is not surprising since both samples were recruited in precisely the same way (via Prolific.co ${ }^{21}$ ). 


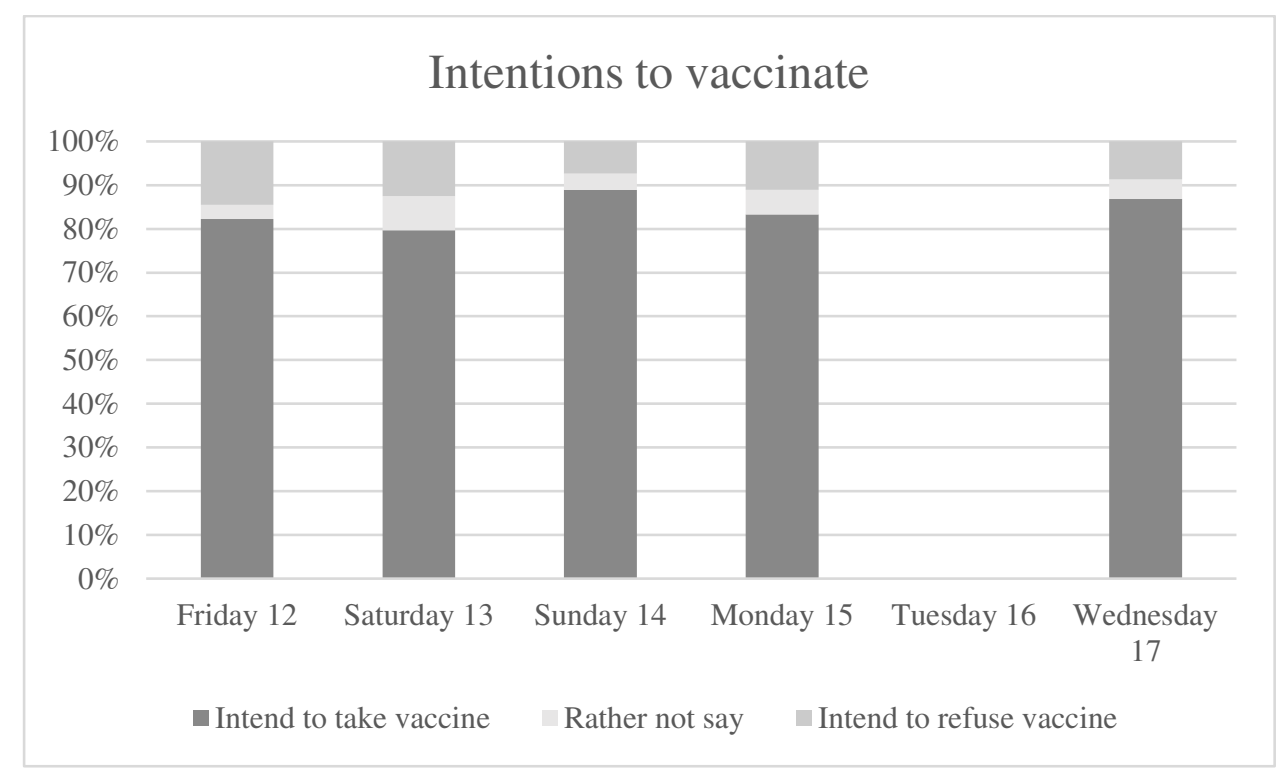

\section{Figure 3: Intentions to Vaccinate by Day of Data Collection}

Figure 3 depicts intentions as measured on each day of the survey. It implies no change in intentions over time.

Our three attitude items show a Cronbach's Alpha of .85, which implies that they are picking up a single factor. We reverse code the item "I am uncertain about the benefits of the Covid vaccine" so that higher numbers always indicate more positive attitudes. We report the mean of the three scale items related to the vaccine in the last column of Table 3 , which describes mean outcomes on each variable for each day of data collection.

Table 3: Summary of Outcome Measures

\begin{tabular}{llllc}
\hline Day & $N$ & \% intend $(95 \% \mathrm{CI})$ & \% refuse $(95 \% \mathrm{CI})$ & Mean attitude $(95 \% \mathrm{CI})$ \\
\hline Friday 12 & 62 & $82.3(72.4-92.0)$ & 14.5 & $3.92(3.65-4.19)$ \\
Saturday 13 & 64 & $79.7(70.0-89.8)$ & 12.5 & $3.82(3.56-4.18)$ \\
Sunday 14 & 54 & $88.9(80.2-97.5)$ & 7.4 & $4.17(3.95-4.40)$ \\
Monday 15 & 18 & $83.3(64.3-100.0)$ & 11.1 & $4.30(3.98-4.61)$ \\
Tuesday 16 & Blood clot / AZ suspension becomes lead story in national news media \\
Wednesday 17 & 237 & $86.1(81.6-90.5)$ & 9.3 & $4.02(3.91-4.15)$
\end{tabular}


The results described in Table 3 imply that there was no change in the intentions and attitudes of the UK public in the aftermath of the blood clot / AZ suspension story. Table 4 reports the results of regression analyses that control for respondent characteristics.

\section{Table 4: Results of Regressions of Intentions and Attitudes}

\begin{tabular}{|c|c|c|c|c|c|c|}
\hline & Intend & intend & attitude & attitude & attitude & attitude \\
\hline After & $\begin{array}{c}0.058 \\
(0.042)\end{array}$ & $\begin{array}{c}0.052 \\
(0.044)\end{array}$ & $\begin{array}{l}-0.019 \\
(0.134)\end{array}$ & $\begin{array}{l}-0.072 \\
(0.136)\end{array}$ & $\begin{array}{c}0.029 \\
(0.114)\end{array}$ & $\begin{array}{l}-0.024 \\
(0.118)\end{array}$ \\
\hline $\begin{array}{l}\text { Online Search } \\
\text { activity that day }\end{array}$ & & $\begin{array}{c}0.001 \\
(0.001)\end{array}$ & & $\begin{array}{c}0.005 \\
(0.003)\end{array}$ & & $\begin{array}{l}0.005 \\
(0.003)\end{array}$ \\
\hline Covariates & & & & & & \\
\hline Age & $\begin{array}{c}0.001 \\
(0.002)\end{array}$ & $\begin{array}{c}0.001 \\
(0.002)\end{array}$ & $\begin{array}{c}0.007 \\
(0.005)\end{array}$ & $\begin{array}{c}0.006 \\
(0.005)\end{array}$ & $\begin{array}{l}0.011 \\
(0.004)^{* *}\end{array}$ & $\begin{array}{l}0.010 \\
(0.004) * *\end{array}$ \\
\hline Female & $\begin{array}{c}0.027 \\
(0.032)\end{array}$ & $\begin{array}{c}0.028 \\
(0.032)\end{array}$ & $\begin{array}{l}-0.047 \\
(0.099)\end{array}$ & $\begin{array}{l}-0.044 \\
(0.099)\end{array}$ & $\begin{array}{l}-0.026 \\
(0.085)\end{array}$ & $\begin{array}{l}-0.028 \\
(0.085)\end{array}$ \\
\hline Unemployed & $\begin{array}{c}0.035 \\
(0.037)\end{array}$ & $\begin{array}{c}0.035 \\
(0.037)\end{array}$ & $\begin{array}{c}0.114 \\
(0.137)\end{array}$ & $\begin{array}{c}0.095 \\
(0.137)\end{array}$ & $\begin{array}{c}0.107 \\
(0.121)\end{array}$ & $\begin{array}{c}0.093 \\
(0.121)\end{array}$ \\
\hline Scotland & $\begin{array}{l}-0.963 \\
(0.007)^{* *}\end{array}$ & $\begin{array}{l}-0.960 \\
(0.008)^{* *}\end{array}$ & $\begin{array}{l}-0.151 \\
(0.280)\end{array}$ & $\begin{array}{l}-0.109 \\
(0.280)\end{array}$ & $\begin{array}{l}-0.220 \\
(0.231)\end{array}$ & $\begin{array}{l}-0.193 \\
(0.231)\end{array}$ \\
\hline England & $\begin{array}{l}-0.366 \\
(0.035)^{* *}\end{array}$ & $\begin{array}{l}-0.355 \\
(0.036) * *\end{array}$ & $\begin{array}{l}-0.328 \\
(0.244)\end{array}$ & $\begin{array}{l}-0.285 \\
(0.245)\end{array}$ & $\begin{array}{l}-0.325 \\
(0.199)\end{array}$ & $\begin{array}{l}-0.294 \\
(0.199)\end{array}$ \\
\hline North & $\begin{array}{l}-0.918 \\
(0.011)^{* *}\end{array}$ & $\begin{array}{l}-0.917 \\
(0.012)^{* *}\end{array}$ & $\begin{array}{l}-0.799 \\
(0.375)^{*}\end{array}$ & $\begin{array}{l}-0.750 \\
(0.375)^{*}\end{array}$ & $\begin{array}{l}-0.780 \\
(0.319)^{*}\end{array}$ & $\begin{array}{l}-0.741 \\
(0.319)^{*}\end{array}$ \\
\hline Had covid & $\begin{array}{c}0.033 \\
(0.044)\end{array}$ & $\begin{array}{c}0.035 \\
(0.044)\end{array}$ & $\begin{array}{l}-0.180 \\
(0.169)\end{array}$ & $\begin{array}{l}-0.160 \\
(0.169)\end{array}$ & $\begin{array}{l}-0.201 \\
(0.141)\end{array}$ & $\begin{array}{l}-0.185 \\
(0.141)\end{array}$ \\
\hline $\begin{array}{l}\text { Scale } \\
\text { manipulation }\end{array}$ & $\begin{array}{l}-0.027 \\
(0.036)\end{array}$ & $\begin{array}{l}-0.026 \\
(0.037)\end{array}$ & $\begin{array}{c}0.127 \\
(0.137)\end{array}$ & $\begin{array}{c}0.141 \\
(0.137)\end{array}$ & $\begin{array}{c}0.051 \\
(0.118)\end{array}$ & $\begin{array}{c}0.065 \\
(0.118)\end{array}$ \\
\hline $\begin{array}{l}\text { Wording } \\
\text { manipulation }\end{array}$ & $\begin{array}{l}-0.033 \\
(0.044)\end{array}$ & $\begin{array}{l}-0.033 \\
(0.044)\end{array}$ & $\begin{array}{l}-0.062 \\
(0.126)\end{array}$ & $\begin{array}{l}-0.063 \\
(0.126)\end{array}$ & $\begin{array}{l}-0.043 \\
(0.105)\end{array}$ & $\begin{array}{l}-0.042 \\
(0.105)\end{array}$ \\
\hline Constant & & & $\begin{array}{l}4.082 \\
(0.299)^{* *}\end{array}$ & $\begin{array}{l}3.740 \\
(0.357)^{* *}\end{array}$ & $\begin{array}{l}4.044 \\
(0.243)^{* *}\end{array}$ & $\begin{array}{l}3.733 \\
(0.296)^{* *}\end{array}$ \\
\hline$R^{2}$ & & & 0.03 & 0.03 & 0.04 & 0.04 \\
\hline$N$ & 433 & 433 & 433 & 433 & 546 & 546 \\
\hline
\end{tabular}

Notes: Intend indicates answering the question "Do you intend to get the Covid vaccine?" yes (vs. no or rather not say). After refers to responses collected on March $17^{\text {th }}$ the day after the blood clot / AZ suspension story was front page news. The regressions of intend reports marginal effects from Probit models. The attitudes measure is the mean score from the items "I believe the Covid-19 vaccine's benefits outweigh any risks", "The Covid-19 vaccine is beneficial" and, reverse-coded, "I feel uncertain about the benefits of being vaccinated against Covid19". The regressions of attitudes report OLS coefficients from a five-point scale. Online Search Activity is a continuous variable describing the daily data depicted in Figure 2. The omitted category for country is Wales. The omitted category for unemployed is people in various forms of employment; all retired respondents had already received the vaccine and so did not answer the intentions question. $* \mathrm{p}<0.05 ; * * \mathrm{p}<0.01$

For these analyses, we pool the data collected between Friday $12^{\text {th }}$ and Monday $15^{\text {th }}$ as before data and compare this against the after data collected on Wednesday $17^{\text {th }}$. Columns 1 and 2 report the results on intending to receive the vaccine (as opposed to refusing or choosing "rather not say"). The results on attitudes for this same sample are reported in columns 3 and 
4. Columns 5 and 6 report the results on attitudes for the sample as a whole $(n=546)$, inclusive of respondents who had already been vaccinated and so had not been asked the intentions question. The models in columns 2, 4 and 6 include an additional variable, Online search activity that day, intended to capture the level of public concern regarding the vaccine on the day that the respondent answered the survey. Online search activity is coded from the raw data depicted in Figure 2. It is an index of the number of Google searches that include the terms "vaccine" and "safe" on the day in question. So Monday $15^{\text {th }}$ March takes a value of 100 and Friday $12^{\text {th }}$ March takes a value of 33, as in Figure 2.

In no case do we find that intentions or attitudes differ across the after group and the before group. Online search activity - a measure of how concerned the UK public was regarding the safety of the vaccine - also failed to predict intentions or attitudes.

\section{Discussion}

We surveyed a cross-section of UK residents immediately before and immediately after a massive negative news event surrounding the most distributed vaccine in the UK. Our data show no discernible difference in the intentions or attitudes in the after group relative to the before group.

One limitation of this study is the sample. An ideal test of the effect of this news event would have recruited a large representative sample. Of course, we could not have known in advance that there was to be a news event and so achieving that ideal was impossible on this occasion. There are two potential concerns: noise resulting from a relatively small sample and bias resulting from a non-representative sample. On the first of these, our sample size is small compared with the 4,000 responses collected by Loomba et al. for the survey experiment that we referred to in the introduction ${ }^{3}$. That said, our sample size is not atypical of public opinion research. The University of Michigan Index of Consumer Sentiment, which is specifically 
designed to identify change in attitudes over time, derives from a monthly survey of 500 respondents $^{22}$. In any case, the key question is whether our study is underpowered to detect a true effect. In other words, if we had recruited 5,000 respondents from Prolific.co instead of 500 , might we have concluded that there was a reduction in intentions and attitudes? The answer is no. If such a reduction were to be observed then we would observe a negative sign on the after coefficient in Table 4. In practice the coefficient is positive. A separate concern is biased sampling. The key question here is whether our convenience sample is atypical regarding their attitudes to the vaccine? One reassurance on this point is that levels of intention reported in our before sample (83\%) are very similar to the rates of intention reported in a recent study on a representative sample of the UK population $(82 \%)^{23}$. A second reassurance is that the results implied by our sample correspond well with other data. A YouGov poll of UK residents conducted within days of the blood clot / AZ suspension event found that $77 \%$ of respondents reported the AZ vaccine to be safe, a result that the report's author interprets as demonstrating that the event had "little to no impact on public confidence" in the $\mathrm{UK}^{24}$. Also, the intentions stated in our survey match well with the high level of demand for vaccines manifest in the UK in the days following the blood clot/ AZ suspension event. Just a few days after this news event took place, more UK residents received the vaccine in a single day than ever before ${ }^{25}$.

A second limitation of this study is that it was not a randomised trial and so we cannot interpret the before / after comparison as a causal measure of the blood clot / AZ suspension event. There will certainly have been contemporaneous factors that changed between the close of before data collection on Monday morning and start of after data collection on Wednesday morning. That said, we can be confident that there was no more publicized news relevant to vaccines (or anything else for that matter) than the blood clot / AZ suspension event that is the focus of this paper. 
The core message of these data is that UK residents' intentions and attitudes to vaccine uptake were unaltered by a widely-broadcast story linking a vaccine to blood clots and death. This is not to say that the event did not damage the effort against Covid-19. The results reported here are specific to the UK and early polling suggests a drop in confidence in other European countries $^{24}$.

These data do raise a puzzle however. Why is it that our data imply no effect of negative information regarding a vaccine where a survey experiment that presented respondents with negative information did find an effect? We can only speculate. One source of difference across the studies is the content of the negative information. For instance, in the Loomba et al. survey experiment ${ }^{3}$ respondents were presented with the misinformation that the vaccine causes 97 percent of users to become infertile. Our study concerned an (unproven) link between the AZ vaccine and an extremely low probability of blood clots leading to death. Notwithstanding that our case concerned a low probability outcome, the possibility of death as an outcome is likely to inspire $\mathrm{dread}^{26}$ and was taken seriously enough to prompt European countries to suspend use of the vaccine. A second point of difference is timing. The Loomba et al. survey experiment was conducted in September $2020^{3}$, before any vaccine had yet been produced. At the time that we collected our data, $23 \mathrm{~m}$ people in the UK had already been vaccinated $^{25}$ and so respondents to our survey had more knowledge with which to form their intentions than was the case for respondents to the survey experiment. That additional knowledge would be expected to deliver more robust - and hence less malleable - intentions. A third source of difference is that the experiment studied the effect of manipulating information within a survey. That has the advantage of allowing for clean causal estimation of information per se but it leaves out of the analysis the real-world responses evoked by such information e.g. how the media covers the information. 
The current research adds an important data point to our understanding of how the public responds to negative news regarding a vaccine. It is the first study we are aware of to describe public response to negative news regarding a Covid-19 vaccine that takes account of the responses of state actors, the scientific community and the media. The data lead us to conclude that in the UK the cumulative effect of the initial story and of the media coverage of that event was zero.

\section{Methods}

\section{Participants}

Our data were collected using the Prolific.co web recruitment platform ${ }^{21}$. In order to be eligible to view our recruitment materials, respondents had to be over 18 and have IP addresses based within the UK (Scotland, England, Northern Ireland and Wales). The study was advertised as academic research on attitudes, expectations and perceptions with regard to the Covid pandemic and included a warning that the survey would cover topics of illness and death. Potential respondents could view further details on the survey front page, which elicited their informed consent. 11 of 557 respondents who viewed the informed consent declined the survey. Data collection for our before group began at $12.43 \mathrm{pm}$ on Friday $12^{\text {th }}$ March and ran to 9.11am on Monday $15^{\text {th }}$ March 2021 and yielded 241 responses. Data collection for our after group began at 10.56am on Wednesday $17^{\text {th }}$ March and ran to $1 \mathrm{am}$ on Thursday $18^{\text {th }}$ March 2021 and yielded 305 responses. Sample size was determined by the constraint that we wanted to collect data only on the day of March $17^{\text {th }}$ in order to have a clean before / after comparison. The total sample comes to 546 usable responses. For reference, the sample size used to construct the Michigan Index of Consumer Sentiment, a 
prominent survey measure of attitude change, is 500. Descriptive statistics of respondent characteristics are presented in Table 2.

\section{Procedures}

The survey instrument was designed to test scale items related to worry and coping in response to the Covid-19 pandemic. After the informed consent page, respondents were asked a series of yes / no questions regarding their own experience of Covid-19 e.g. had they been diagnosed with Covid? The last of these questions asked "Do you intend to get the Covid-19 vaccine?" answered as yes / no / rather not say. This is the primary outcome variable in our analysis.

Over the screens that followed respondents were asked the extent to which they agreed with a series of statements. For instance, the opening item was "I find it hard to cope with the uncertainty caused by the pandemic". On the third such screen, respondents were asked three questions that are relevant to the current research:

"I believe the Covid-19 vaccine's benefits outweigh any risks"

"I feel uncertain about the benefits of being vaccinated against Covid-19"

and

"The Covid-19 vaccine is beneficial".

These items were answered on a five-point scale and are secondary outcomes in our analysis.

For completeness we report three superficial tweaks made to the after survey instrument relative to the before instrument. First, we dropped four screens of statements that followed our items of interest. Second, in a preregistered experiment in the before survey we had randomised between two response scales for the attitude questions. Some respondents 
answered on the scale "disagree strongly" to "agree strongly" and others answered on the scale "do not agree at all" to "absolutely agree". Our preregistration predicted that the specific survey item "The Covid-19 vaccine is beneficial" would be sensitive to scale choice. The results of this test showed no difference in the mean level of agreement. A Kolmogorov-Smirnov test for equality of distribution functions on this item finds an exact $p$-value of 0.780 .

For the after survey we opted to use just the "disagree strongly" to "agree strongly" scale. Lastly, we randomised the wording of an unrelated item in the first bank of statements in the after survey. In the before survey all respondents read "I continue to feel at risk from Covid19". Some respondents in the after survey saw this item as "I feel at risk from Covid-19". None of these manipulations could have influenced responses on our primary dependent variable because we asked about intention before respondents saw any of these three variations. Also, the two question wording variations were randomly assigned and so we control for their effect in Table 4.

\section{Ethics}

The study was approved by the General University Ethics Panel at the University of Stirling under ethics application "Impact of COVID Fear 0485" on Thursday March $11^{\text {th }}$. All research was performed in accordance with the relevant regulations ${ }^{27}$ and informed consent was obtained from all participants.

\section{Analyses}

We conducted all analyses using STATA 15.1.

\section{References}


1 UK Medicines and Healthcare Products Regulatory Agency. UK medicines regulator gives approval for first UK COVID-19 vaccine

https://www.gov.uk/government/news/uk-medicines-regulator-gives-approval-forfirst-uk-covid-19-vaccine (2020).

2 UK Department of Health and Social Care. Oxford University/AstraZeneca vaccine authorised by UK medicines regulator https://www.gov.uk/government/news/oxforduniversityastrazeneca-vaccine-authorised-by-uk-medicines-regulator(2020).

3 Loomba, S., de Figueiredo, A., Piatek, S. J., de Graaf, K., \& Larson, H. J. Measuring the impact of COVID-19 vaccine misinformation on vaccination intent in the UK and USA. Nature Human Behaviour 5, 1-12 (2021).

4 Kwok, K. O., Lai, F., Wei, W. I., Wong, S. Y. S., \& Tang, J. W. Herd immunityestimating the level required to halt the COVID-19 epidemics in affected countries. Journal of Infection, 80(6), e32-e33 (2020).

5 BBC News. Covid vaccine: how many people in the UK have been vaccinated so far? https://www.bbc.co.uk/news/health-55274833 (2021)

6 BBC Radio 4. Six O'Clock News [radio broadcast] (15 ${ }^{\text {th }}$ March, 2021)

7 Macdonald, V. Germany, France and Italy temporarily suspend use of AstraZeneca vaccine. Channel 4 News https://www.channel4.com/news/germany-france-anditaly-temporarily-suspend-use-of-astrazeneca-vaccine (2021)

8 Another shot in the foot: How Europe's vaccine caution can cost lives. The Economist (2021)

9 Financial Times UK print edition March $16^{\text {th }} 2021$ front page accessed https://digital.olivesoftware.com/Olive/ODN/FTUK/Default.aspx

10 Thepaperboy.com. Front Pages from March $16^{\text {th }} 2021$ for various UK print edition newspapers https://www.thepaperboy.com/uk/2021/03/16/front-pages-archive.cfm (2021)

11 BBC Radio 4 PM [radio broadcast] Suspension by several major EU countries of the Oxford-AstraZeneca vaccine with Professor Adam Finn. (2021)

12 Mancini D.P. \& H. Kuchler, Countries suspend jabs despite a lack of evidence. Financial Times (2021)

13 Leask, J. Restoring confidence after the covid-19 Oxford/AstraZeneca vaccine pause will be an uphill battle. BMJOpinion (2021)

14 Euractiv. Denmark, Norway and Iceland suspend AstraZeneca COVID shots after blood clot reports. https://www.euractiv.com/section/coronavirus/news/denmarknorway-and-iceland-suspend-astrazeneca-covid-shots-after-blood-clot-reports/ (2021)

15 Boland, L. Vaccine target for this week reduced by 30,000 doses due to precautionary pause in AstraZeneca use. https://www.thejournal.ie/astrazenecasuspension-ireland-5380974-Mar2021/ (2021)

16 The World This Weekend. March $14^{\text {th }}$ Episode. (2021) 
17 European Medicines Agency. EMA's safety committee continues investigation of COVID-19 Vaccine AstraZeneca and thromboembolic events - further update. https://www.ema.europa.eu/en/news/emas-safety-committee-continuesinvestigation-covid-19-vaccine-astrazeneca-thromboembolic-events (2021)

18 BBC Radio 4 Today. 15/03/2021. (2021)

19 European Medicines Agency. COVID-19 Vaccine AstraZeneca: benefits still outweigh the risks despite possible link to rare blood clots with low blood platelets. https://www.ema.europa.eu/en/news/covid-19-vaccine-astrazeneca-benefits-stilloutweigh-risks-despite-possible-link-rare-blood-clots (2021)

20 Thepaperboy.com. Front Pages from March $19^{\text {th }} 2021$ for UK print edition newspapers https://www.thepaperboy.com/uk/2021/03/19/front-pages-archive.cfm (2021)

21 Peer, E., Brandimarte, L., Samat, S., \& Acquisti, A. Beyond the Turk: Alternative platforms for crowdsourcing behavioral research. Journal of Experimental Social Psychology, 70, 153-163 (2017).

22 Curtin, R. T. Indicators of consumer behavior: The University of Michigan surveys of consumers. Public Opinion Quarterly, 46(3), 340-352 (1982).

23 Robertson, E., Reeve, K. S., Niedzwiedz, C. L., Moore, J., Blake, M., Green, M., ... \& Benzeval, M. J. Predictors of COVID-19 vaccine hesitancy in the UK Household Longitudinal Study. medRxiv, 2020-12 (2021).

24 Smith, M. Europeans now see AstraZeneca vaccine as unsafe, following blood clots scare https://yougov.co.uk/topics/international/articlesreports/2021/03/22/europeans-now-see-astrazeneca-vaccine-unsafe-follo (2021)

25 BBC News. Covid-19: Record-breaking day with 844,285 vaccine doses given in UK https://www.bbc.co.uk/news/uk-56477291 (2021)

26 Slovic, P. Perception of risk. Science, 236(4799), 280-285 (1987).

27 British Psychological Society. Code of Human Research Ethics. Accessed at: https://www.bps.org.uk/sites/bps.org.uk/files/Policy/Policy\%20\%20Files/BPS\%20Code\%20of\%20Human\%20Research\%20Ethics.pdf 
Figures
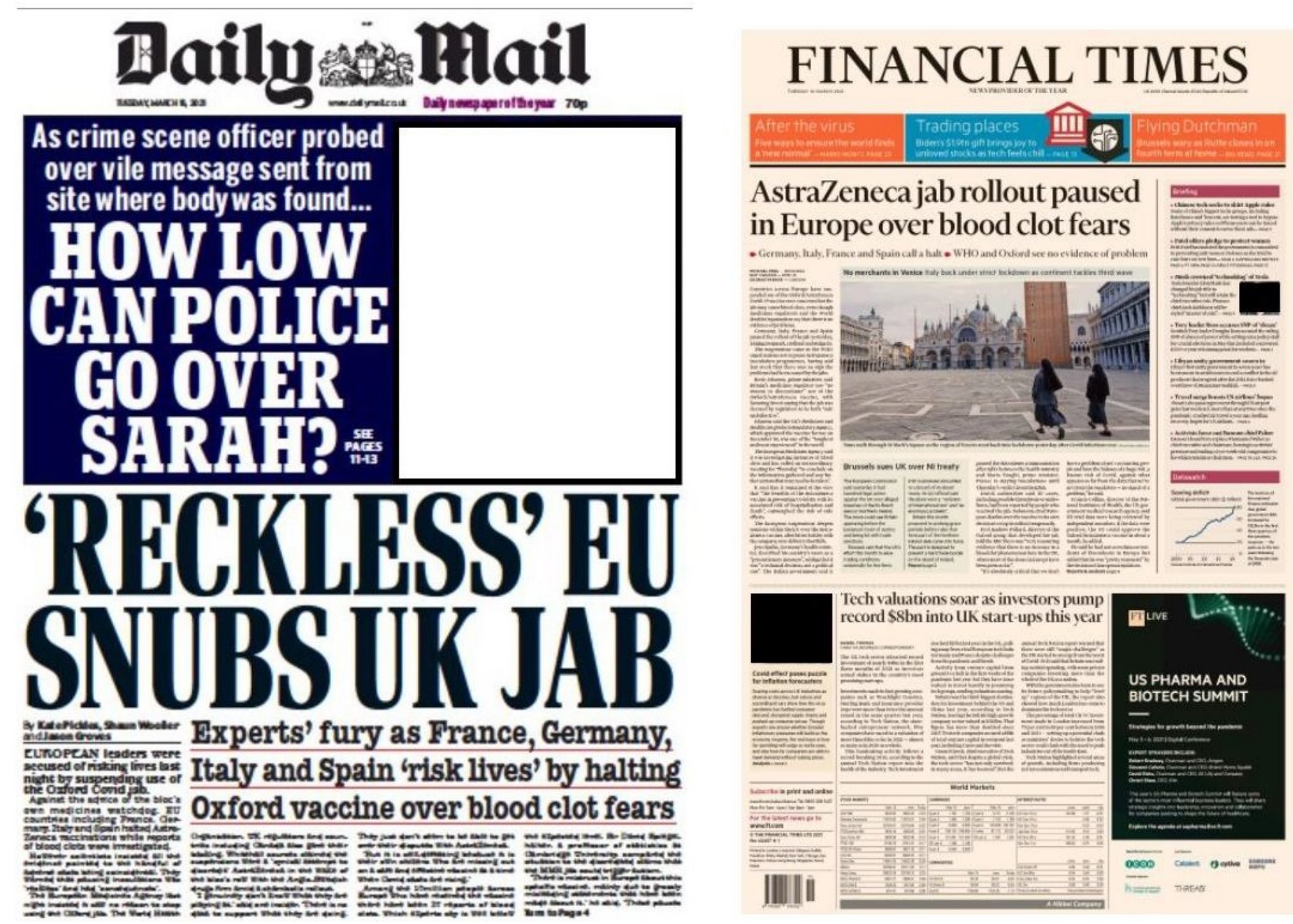

Figure 1

Screenshot of Front Page of the Daily Mail6 (left) and Financial Times7 (right) print editions from Tuesday March 16th. 
vaccine safe

Search term $\vdots \quad+$ Compare
United Kingdom v

Interest over time

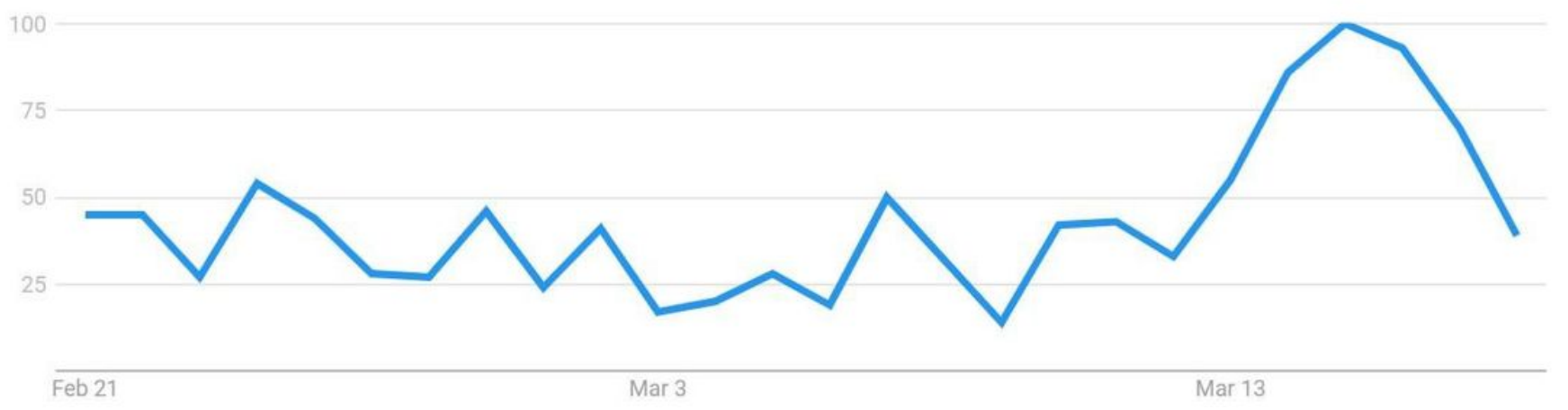

Figure 2

Google Trends Graph mapping searches including the words "vaccine" and "safe" originating within the UK in the period February 21st to March 21st. Note: We use this search term because it encompasses various more specific formulations e.g. "is the Covid vaccine safe?" and "is the Oxford AstraZeneca vaccine safe?" 


\section{Intentions to vaccinate}

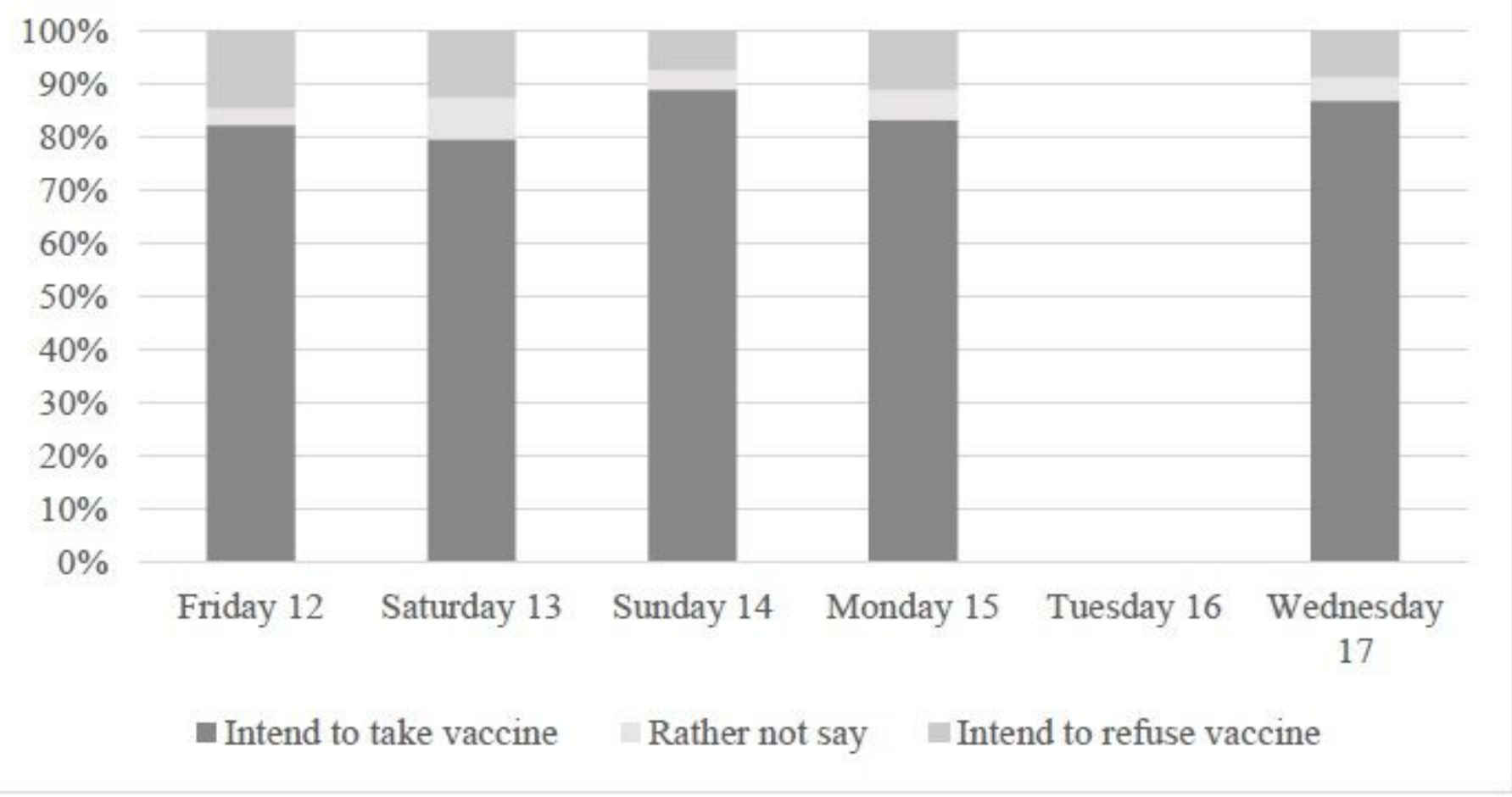

\section{Figure 3}

Intentions to Vaccinate by Day of Data Collection 